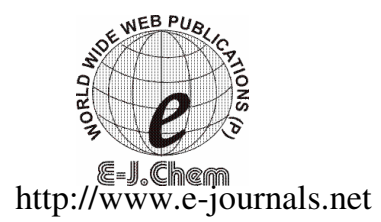

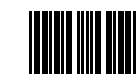

ISSN: 0973-4945; CODEN ECJHAO

E-Journal of Chemistry 2010, 7(S1), S349-S357

\title{
Preparation and Characterization of Chitosan/ Polyvinyl Alcohol Blends-A Rheological Study
}

\author{
ESAM A. EL-HEFIAN*, MOHAMED MAHMOUD NASEF ${ }^{\S}$ \\ and ABDUL HAMID YAHAYA \\ Department of Chemistry, Faculty of Science \\ University of Malaya, 50603 Kuala Lumpur, Malaysia \\ ${ }^{\S}$ Chemical Engineering Department \\ Faculty of Chemical and Natural Resources Engineering \\ Universiti Teknologi Malaysia, 81310 UTM Skudai, Johor, Malaysia \\ eelhefian@yahoo.com
}

Received 30 March 2010; Accepted 24 May 2010

\begin{abstract}
Blends of chitosan (CS) and polyvinyl alcohol (PVA) of different proportions (considering chitosan as the main component) were prepared. The rheological properties of the obtained blend solutions such as the shearing viscosity and the shear stress were investigated as a function of shear rate under various temperatures, shearing times and solution storage times using a digital viscometer. The CS/PVA solutions showed a Newtonian behavior at temperatures in the range of $40-55^{\circ} \mathrm{C}$ regardless of the blend composition. This was accompanied by a general decrease in the viscosity with increasing PVA content in the blend. The heatdependant viscosity changes of the blend solutions were found to follow Arrhenius equation. The shearing time was found to have no significant effect on the shearing viscosity of all blended solutions. However, the variation of solution storage period was found to have a mixed effect when time was extended to 3 weeks.
\end{abstract}

Keywords: Chitosan, PVA, Solution blending, Rheological properties, Thermal properties

\section{Introduction}

Polymer blends are a class of materials that is receiving an increasing attention. This is because such materials possess improved physicochemical properties and as a result they are more suitable for industrial applications than their individual components. Polymer blends can be tailor made to maintain specific properties, which are affected by the interaction i.e. compatibility among the individual polymer components selected for blending ${ }^{1,2}$. Blending of natural polymers with synthetic ones is an interesting method to obtain new materials in which the former properties are improved to suit particular applications ${ }^{3}$. Among natural polymer, chitosan occupies special position duo to its versatility in that it enhances its medicinal value by blending with synthetic and natural polymers to extend its applications. 
Chitosan is an organic polysaccharide usually obtained by alkaline deacetylation of the second most abundant naturally occurring chitin of crab and shrimp shells ${ }^{4}$. Due to the amino groups that chitosan possesses in its chain, it can be dissolved in dilute aqueous acid solutions, such as formic acid and acetic acid. Since it is inexpensive, non-toxic and possesses potentially reactive amino functional groups, chitosan has been evaluated for numerous applications ${ }^{5-7}$.

Polyvinyl alcohol (PVA) is a non-ionic synthetic polymer that is soluble in water. It has a large number of hydroxyl groups which allows it to react with many types of functional groups. This advantage makes it suitable as biocompatible materials. PVA has been widely used in diverse fields, ranging from thickening agent to solution-spun fiber. Viscosity plays an important role in the industrial applications of PVA. There are several factors that influence the rheological behavior of aqueous PVA solutions including molecular weight, temperature and degree of hydrolysis ${ }^{8,9}$. The objective of the present study is to report on the rheological properties of chitosan and PVA blends having various proportions using a digital viscometer.

\section{Experimental}

Shrimp source chitosan was purchased from a local company with a deacetylation percentage (DD) of $88.1 \%$ defined by UV method ${ }^{10}$. This chitosan is acid-soluble, white-colored and flaky. PVA Fluka (56-98) with an average molecular weight of $195 \times 10^{3} \mathrm{~g} \mathrm{~mol}^{-1}$ was used in this work. Acetic acid (glacial 100\%, pro analysi) was purchased from Merck (Darmstadt, Germany). Ultra pure water (Maxima Ultra Pure Water, Elga-Prima Corp, UK) with a resistivity greater than $18 \mathrm{M} \Omega / \mathrm{cm}$ was used to prepare all solutions. All chemicals were used without further purification and freshly prepared solutions were used in all experiments.

\section{Preparation of the solutions}

Chitosan was dried in the oven until a constant weight was observed. Then, $5 \mathrm{~g}$ of chitosan was dissolved in $500 \mathrm{~mL}$ acetic acid $(0.1 \mathrm{M})$ followed by mild stirring and heating at about $60{ }^{\circ} \mathrm{C}$ overnight to form a $10 \mathrm{~g} \mathrm{~L}^{-1}$ chitosan solution. The solution was then filtered to remove dust and other traces of impurities. Air bubbles were eliminated by keeping the solutions at room temperature for $2 \mathrm{~h}$.

For preparing PVA solution, the same amount and procedure as for chitosan were applied with exception of using acetic acid, wherein preheated ultra pure water was used. The solutions were then stirred and heated at about $80{ }^{\circ} \mathrm{C}$ for $2 \mathrm{~h}$.

\section{Preparation of the blended solutions}

Blended solutions were prepared by adding the aqueous PVA solution drop by drop to a chitosan solution, which was kept on a magnetic stirrer, at about $94{ }^{\circ} \mathrm{C}$ and the mixture was stirred at a moderate speed for $30 \mathrm{~min}$. The final composition of chitosan and PV (CS/PVA) varied from $90 / 10$ to $50 / 50$ by volume. Table 1 shows the designated compositions for all the solutions prepared in this study.

Table 1. Composition of the chitosan and PVA mixtures

\begin{tabular}{ccc}
\hline Solution designation & $\mathrm{V}_{\mathrm{CS}}$, vol \% & $\mathrm{V}_{\mathrm{PVA}}$, vol \% \\
\hline Cs/PVA 90/10 & 90 & 10 \\
Cs/PVA 80/20 & 80 & 20 \\
Cs/PVA 70/30 & 70 & 30 \\
Cs/PVA 60/40 & 60 & 40 \\
Cs/PVA 50/50 & 50 & 50 \\
\hline
\end{tabular}




\section{Molecular weight measurements}

The molecular weight of chitosan was about $5.5 \times 10^{5} \mathrm{~g} \mathrm{~mol}^{-1} \mathrm{~mol}^{-1}$ determined by gel permeation chromatography $(\mathrm{GPC})^{11}$.

\section{Rheological measurements}

Rheological measurements were performed on a Brookfield digital viscometer, model DV-II + Pro, with an attached UL adapter. The viscosity was determined in $20 \mathrm{~mL}$ of the sample and the shearing time was 15 seconds. For the storage time measurements, solutions were kept at room temperature in glass bottles in a dark place until analysis. Each measurement was recorded as an average value of five readings when a constant shear rate was applied.

\section{Results and Discussion}

\section{The effect of temperature on the apparent viscosity of CS/PVA blended solutions}

The shear rate-dependent viscosity of CS/PVA mixture solutions as a function of the shear rate at a temperature range of $45{ }^{\circ} \mathrm{C}$ to $55{ }^{\circ} \mathrm{C}$ is presented in Figure 1 (a-g). Similar to that of many polymer solutions, the behavior of the viscosity-temperature interrelationship for these mixtures shows a decrease of viscosity with an increase of temperature. On the other hand, the Newtonian behavior is observed at all temperatures studied for all ratios. In addition, the viscosity of all blend compositions was found to lie between the viscosities of pure components over the entire compositional range.
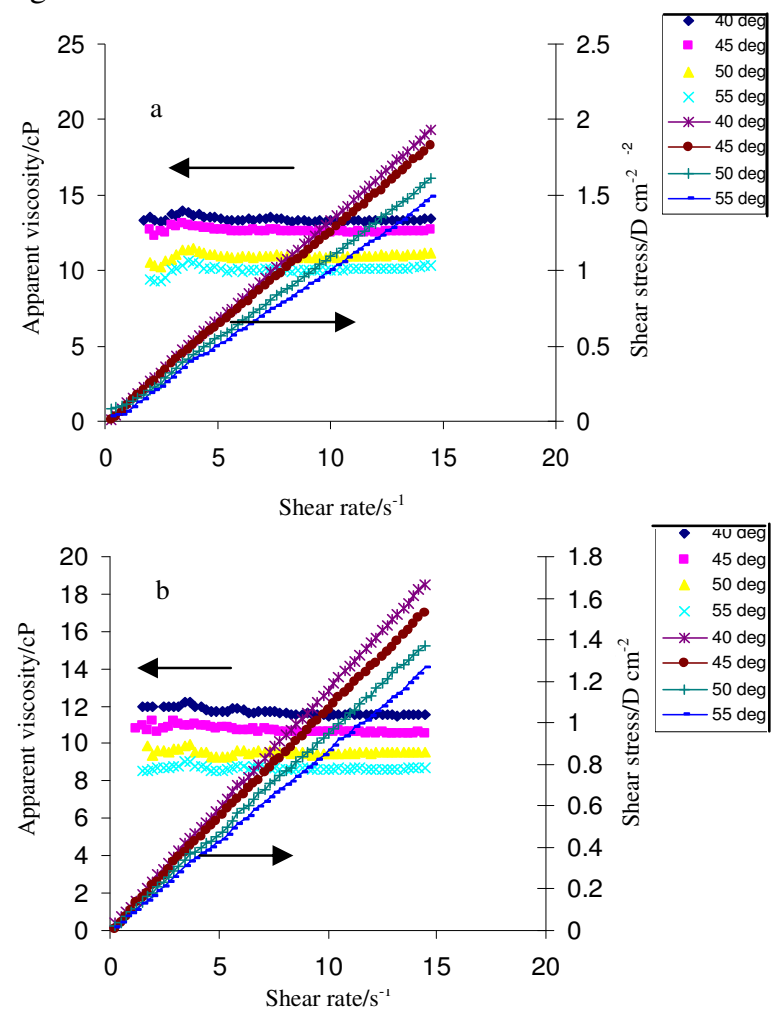

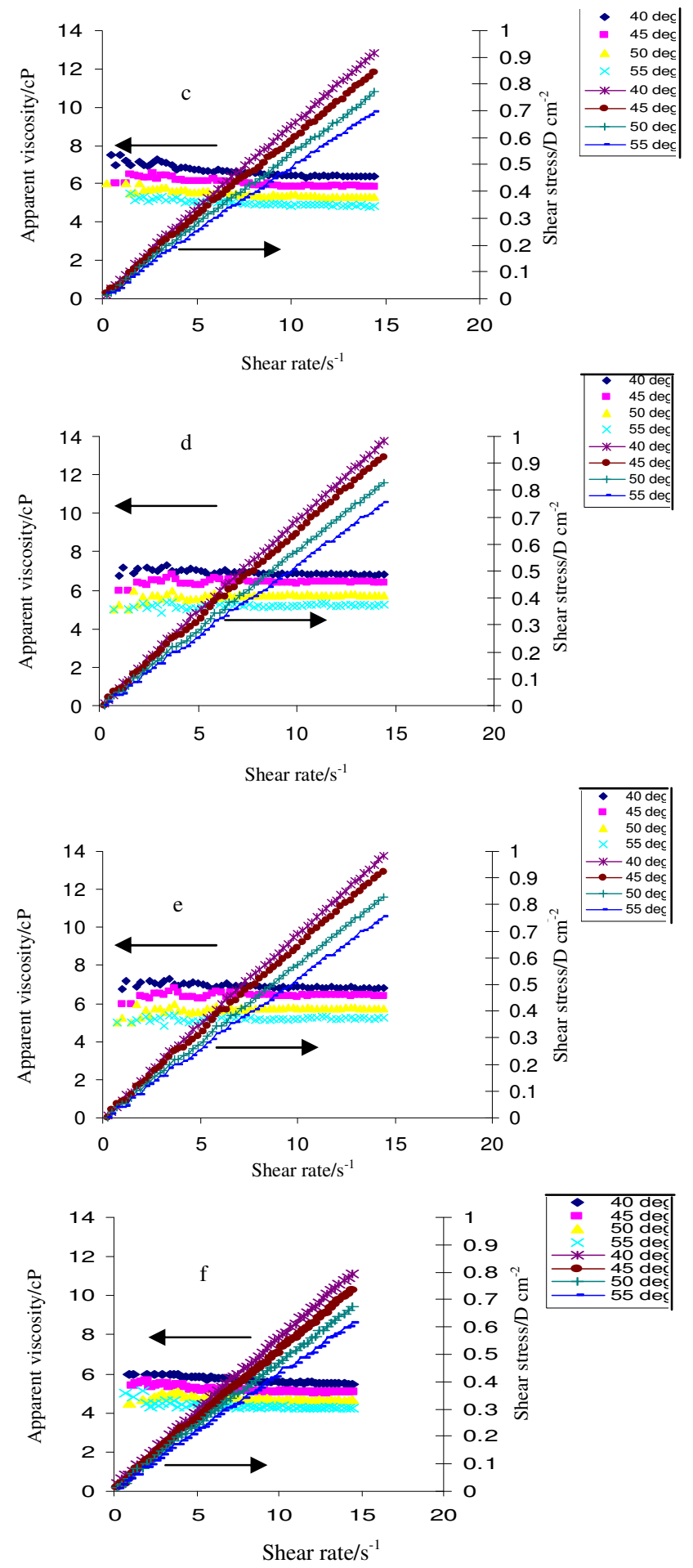


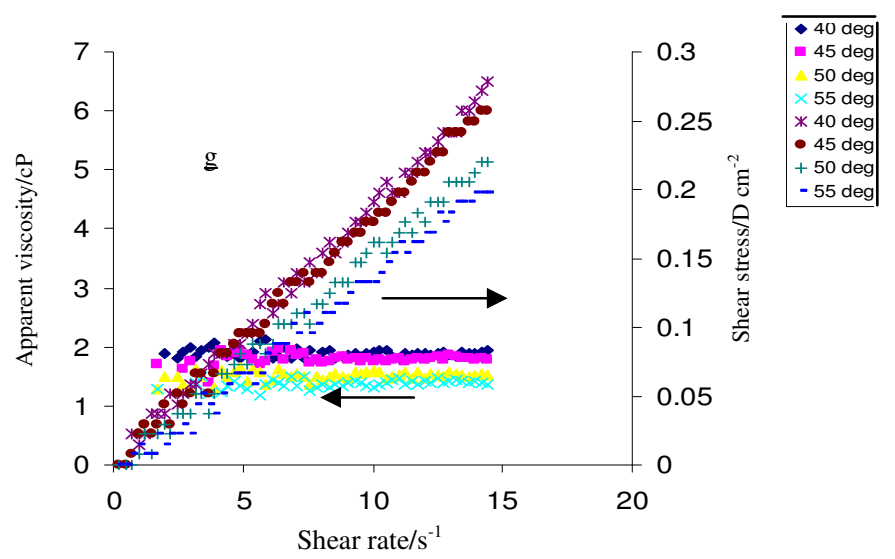

Figure 1. The influence of the shear rate and temperature on the rheological curves of (a) pure chitosan solution; (b) (90/10); (c) 80/20; (d) 70/30; (e) 60/40; (f) 50/50 and (g) pure PVA solutions.

Figure 1 (a-g) shows the effect of temperature on the shear stress of CS/PVA mixtures as a function of shear rate. The shear stress increased with increasing shear rate for all ratios. At the same shear rate, shear stresses were higher at lower temperatures. From the graph it is clear that all of the solutions exhibit Newtonian behavior at this range of temperature. Rheograms (plots of shear stress versus shear rate) of all the blends were also found to lie between the rheograms of pure components.

The relationship between the apparent viscosity determined at a constant shear rate $\left(6.15 \mathrm{~s}^{-1}\right)$ and temperature for CS/PVA blend solutions and the pure components is demonstrated in Figure 2 (a). This plot shows a nearly linear relationship whereby the viscosity of the mixture solutions decreases with increasing temperature, i.e., it is a strong function of temperature. It can also be noted that the most effected solution by temperature is the pure chitosan solution while the lowest effected solution by temperature is the pure PVA solution in terms of viscosity. This may indicate that increasing PVA concentration yields solutions which are less sensitive to the temperature. The viscosity values obtained at a constant shear rate $\left(6.15 \mathrm{~s}^{-1}\right)$ can be correlated with temperature according to the Arrhenius equation:

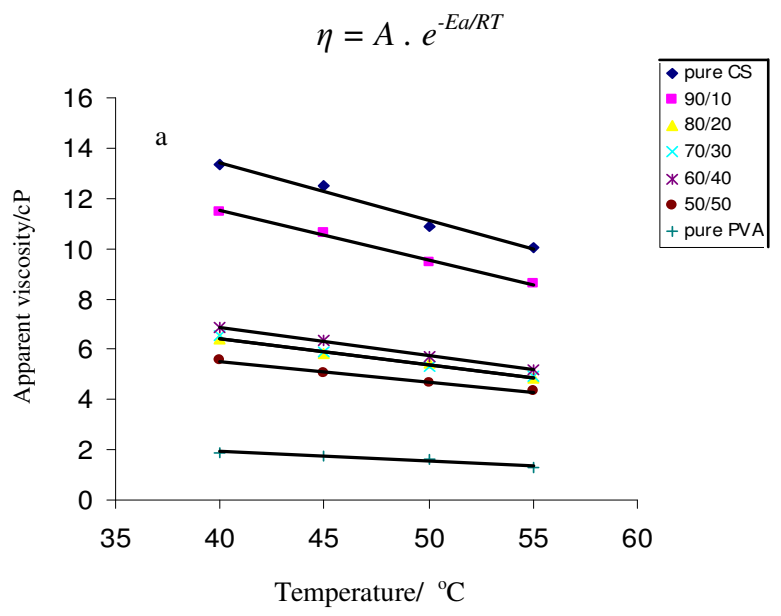




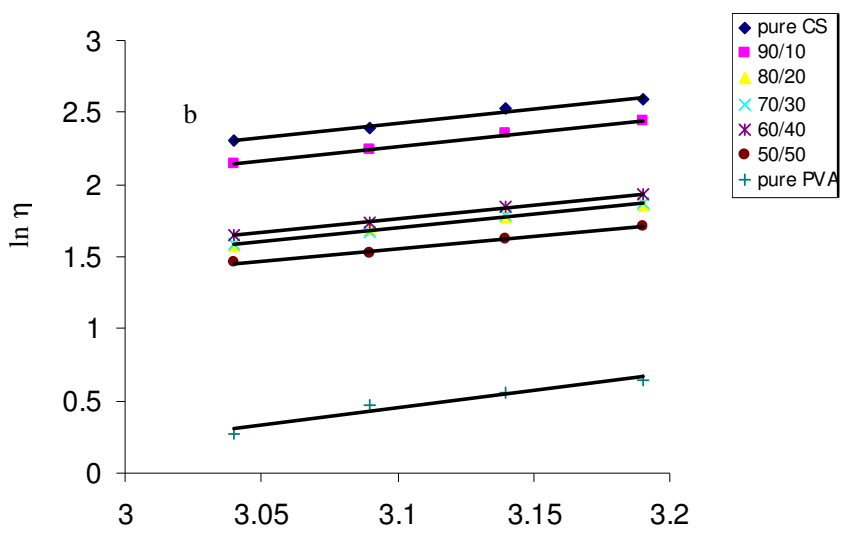

Figure 2. (a) The influence of temperature on viscosity of CS/PVA mixture solutions at a constant shear rate and (b) the Arrhenius plot of $\ln \eta$ versus $1 / \mathrm{T}$ for the same mixture solutions

Table 2. Values of the activation energy of chitosan, PVA and their blends at $6.15 \mathrm{~s}^{-1}$

\begin{tabular}{cc}
\hline Blend ratio (CS/PVA) & $\mathrm{E}_{\mathrm{a}}, \mathrm{kJ} \mathrm{mol}^{-1}$ at $6.15 \mathrm{~s}^{-1}$ \\
\hline $100 / 0$ & 16.80 \\
$90 / 10$ & 16.30 \\
$80 / 20$ & 15.63 \\
$70 / 30$ & 15.63 \\
$60 / 40$ & 16.63 \\
$50 / 50$ & 14.13 \\
$0 / 100$ & 19.29 \\
\hline
\end{tabular}

Where $A$ is a constant related to molecular motion, $E_{a}$ is the activation energy for viscous flow at a constant shear rate, $R$ is the gas constant and $T$ is the absolute temperature in Kelvin. A plot of $l n$ viscosity as a function of $1 / T$ should produce a straight line and from its slope $E_{\mathrm{a}}$ can be calculated. Figure 2 (b) presents the Arrhenius plot for various proportions of CS/PVA mixture solutions. This graph also shows linear relationships. The values of the apparent activation energy are shown in Table 2. As it can be seen in Table 2, all the blended solutions have lower values of $E_{\mathrm{a}}$, which may reflect the good compatibility of the two polymers. The value of the activation energy of chitosan is in accordance with similar data reported in literature ${ }^{12,13}$.

The effects of shearing and storage time on the apparent viscosity of CS/PVA solutions

Viscosity measurements were performed as a function of shear rate for 15, 30, 45, 60 and 75 seconds at $40{ }^{\circ} \mathrm{C}$ to study the shearing time effect [Figure $3(\mathrm{a}-\mathrm{g})$ ]. At all shearing times, CS/PVA blend solutions exhibit similar behavior and no significant change was observed. In addition, when the period of storage was extended to three weeks at a constant shear rate, a general decrease in viscosity was observed as the PVA content increases (Figure 4). Pure chitosan showed gradual increase in viscosity as a function of time while almost a constant value of viscosity was recorded for pure PVA. However, all CS/PVA blend solutions recorded a decrease in viscosity as the period of time was extended to three weeks in general. 

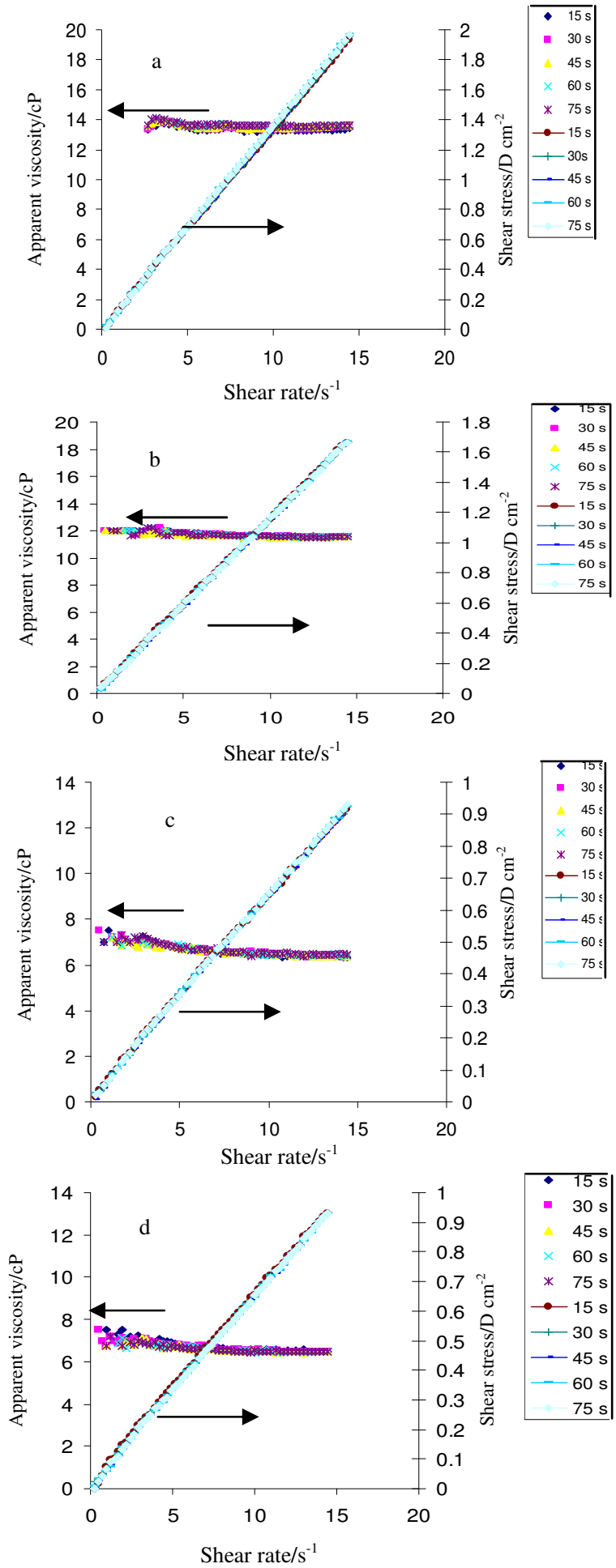

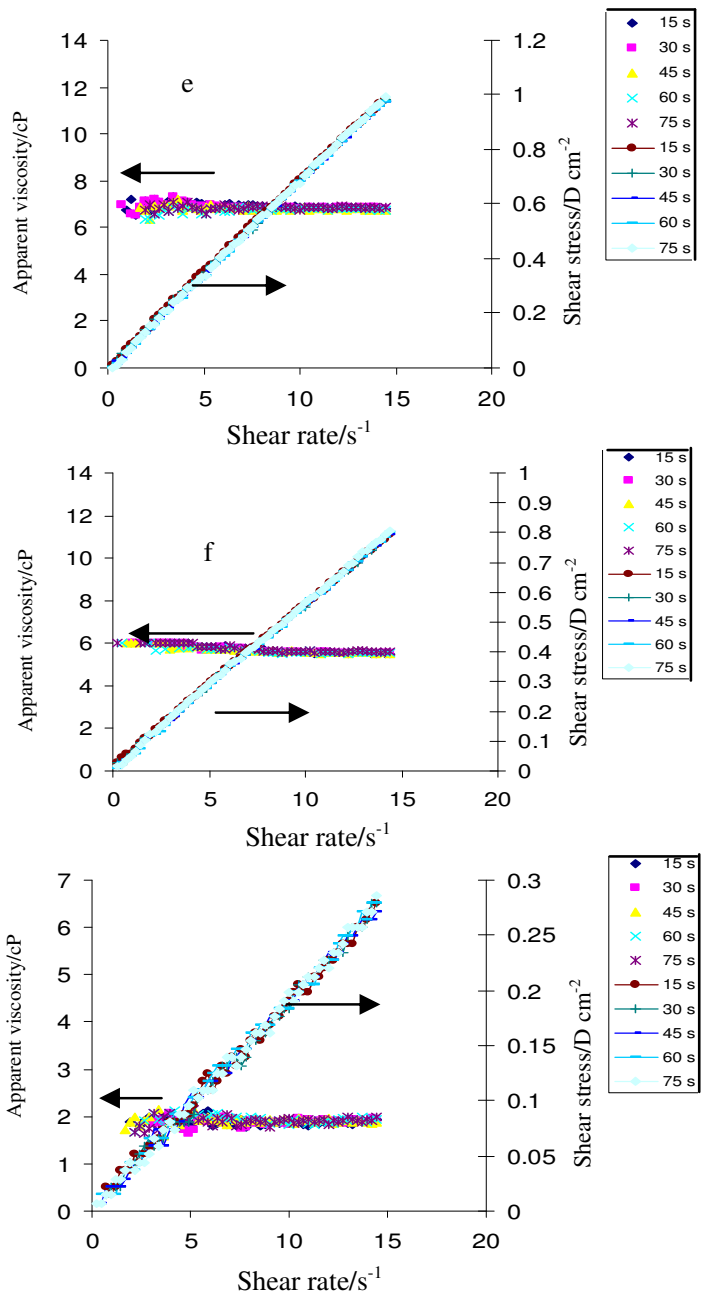

Figure 3. The influence of the shear rate and shearing time on the rheological curves of (a) pure chitosan solution; (b) (90/10); (c) 80/20; (d) 70/30; (e) 60/40; (f) 50/50 and (g) pure PVA solutions at $40{ }^{\circ} \mathrm{C}$

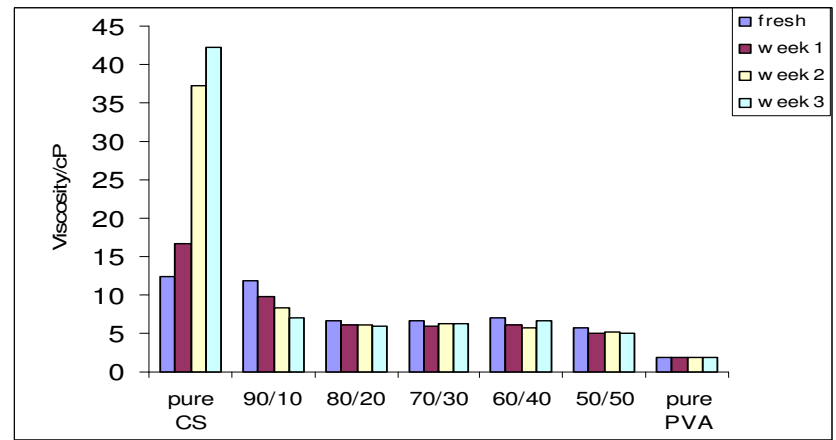

Figure 4. The effect of storage time on the shearing viscosity (determined at $6.15 \mathrm{~s}^{-1}$ ) of CS/PVA mixture solutions (SD is very small) 


\section{Conclusion}

Blended films of chitosan/polyvinyl alcohol (CS/PVA) were prepared at various proportions. Investigations of the obtained blended solutions and films were carried out with rheology, FTIR and DSC. Results have shown that the dynamic rheological measurements of chitosan, PVA and their mixture solutions suggest a Newtonian behavior at temperatures between $40{ }^{\circ} \mathrm{C}$ and $55{ }^{\circ} \mathrm{C}$. All mixture solutions were found to obey the Arrhenius equation. This study has also shown that curves of the apparent viscosity of chitosan, PVA and their blended solutions show similar behavior at all shearing times of 15-75 s. When the storage period was extended to three weeks, different behaviors were observed for the pure components and the blended solutions; chitosan showed a gradual increase in viscosity while almost a constant value of viscosity was recorded for pure PVA. However, all CS/PVA blend solutions recorded a decrease in viscosity with time in general.

\section{Acknowledgment}

The authors are grateful to University of Malaya for supporting this research project under the research grant, PS188/2008A.

\section{References}

1. Hosokawa J, Nishiyama M, Yoshihara K and Kubo T, Ind Eng Chem Res., 1990, 29(2), 800-805.

2. Hasegawa M, Isogai A, Onabe F, Usuda M and Atalla R H, J Appl Polym Sci., 1992, 45, 1873.

3. Yang X, Zhu Z, Liu Q, Chen X and Ma M, Radiat Phys Chem., 2008, 77, 954-960.

4. Pillai O and Panchagnula R, Curr Opin Chem Biol., 2001, 5, 447-450.

5. Khor E and Lim L Y, Biomater., 2003, 24(13), 2339-2349.

6. Yuan S and Wei T, J Bioact Compat Polym., 2004, 19, 467-479.

7. Crini G, Bioresour Technol., 2006, 97(9), 1061-1085.

8. Prokopova E, Stern P and Quadrat O, Colloid Polym Sci., 1985, 263(11), 899-904.

9. Lozinsky V I, Vainerman E S, Domotenko L V, Mamtsis A M, Titova E F, Belavtseva E M and Rogozhin S V, Colloid Polym Sci., 1986, 264, 19-24.

10. Muzzarelli R A A and Rochetti R, Carbohydr Polym., 1985, 5, 461-472.

11. El-hefian E A, Nasef M M and Yahaya A, E-J Chem., 2010, 7(4), 1212-1219.

12. Desbrie`res J, Biomacromol., 2002, 3, 342.

13. Wang W and Xu D, Int J Biol Macromol., 1994, 16(3), 149-152. 


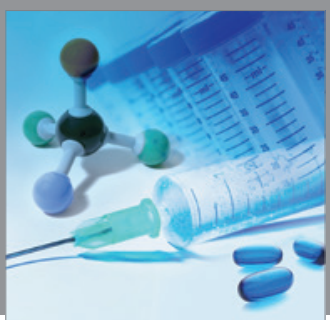

International Journal of

Medicinal Chemistry

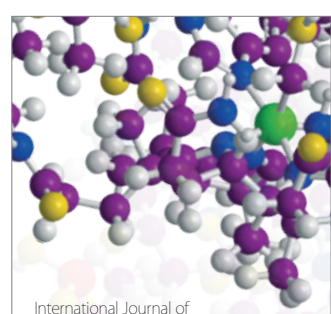

Carbohydrate Chemistry

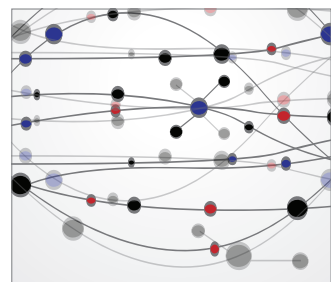

The Scientific World Journal
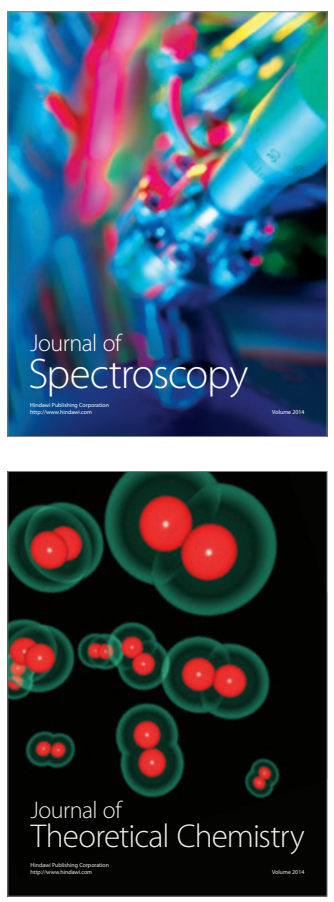
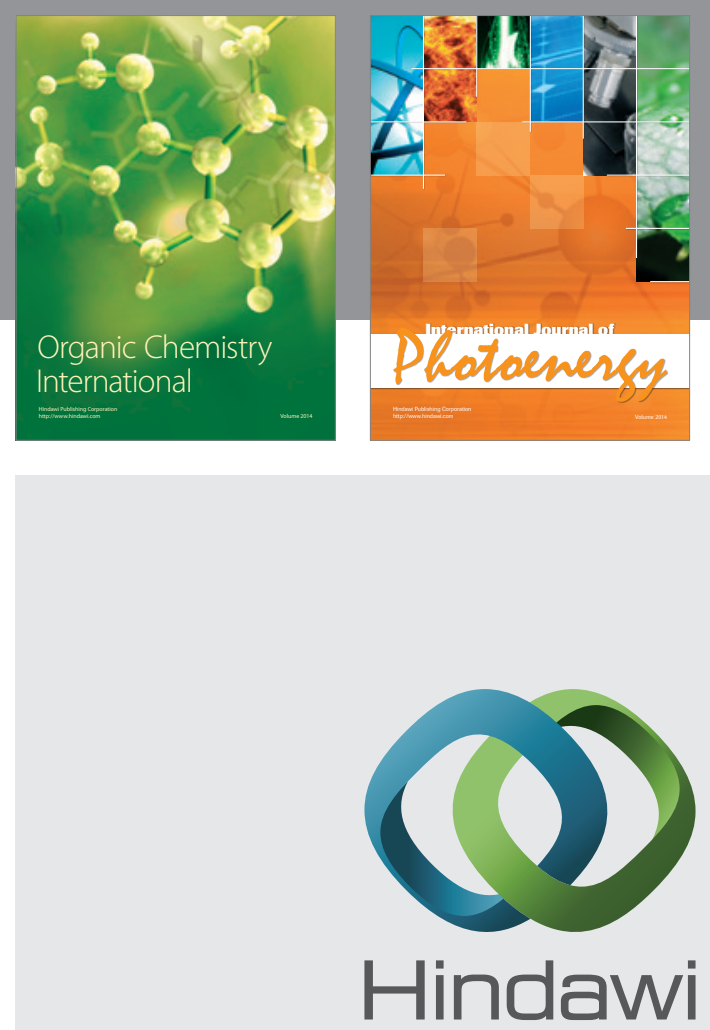

Submit your manuscripts at

http://www.hindawi.com
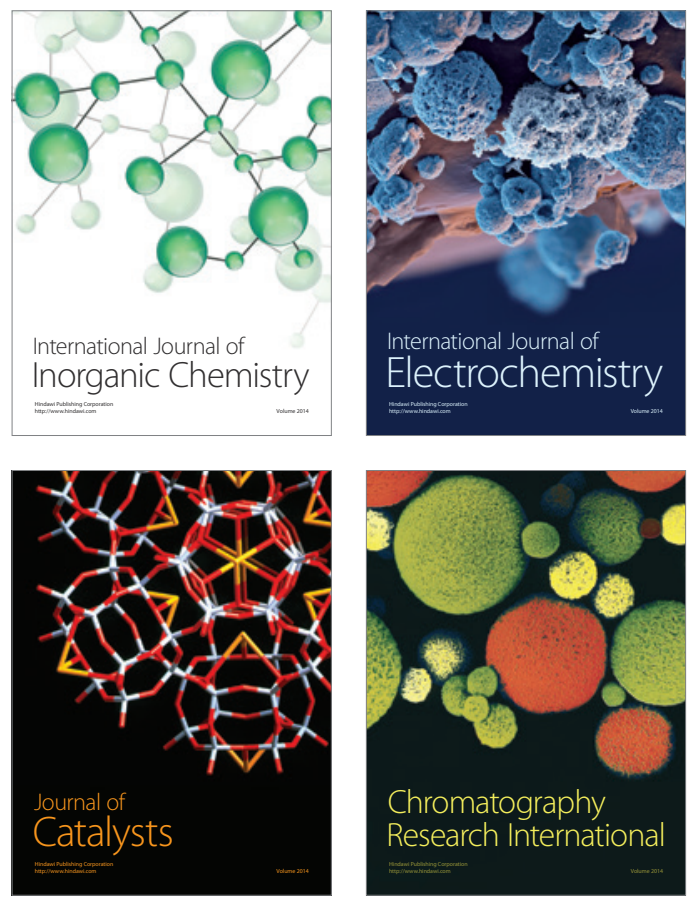
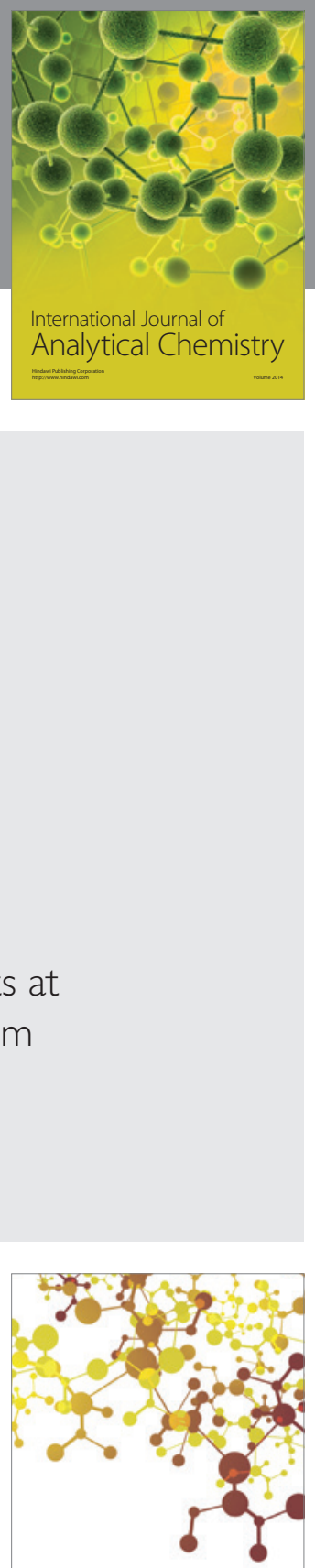

Journal of

Applied Chemistry
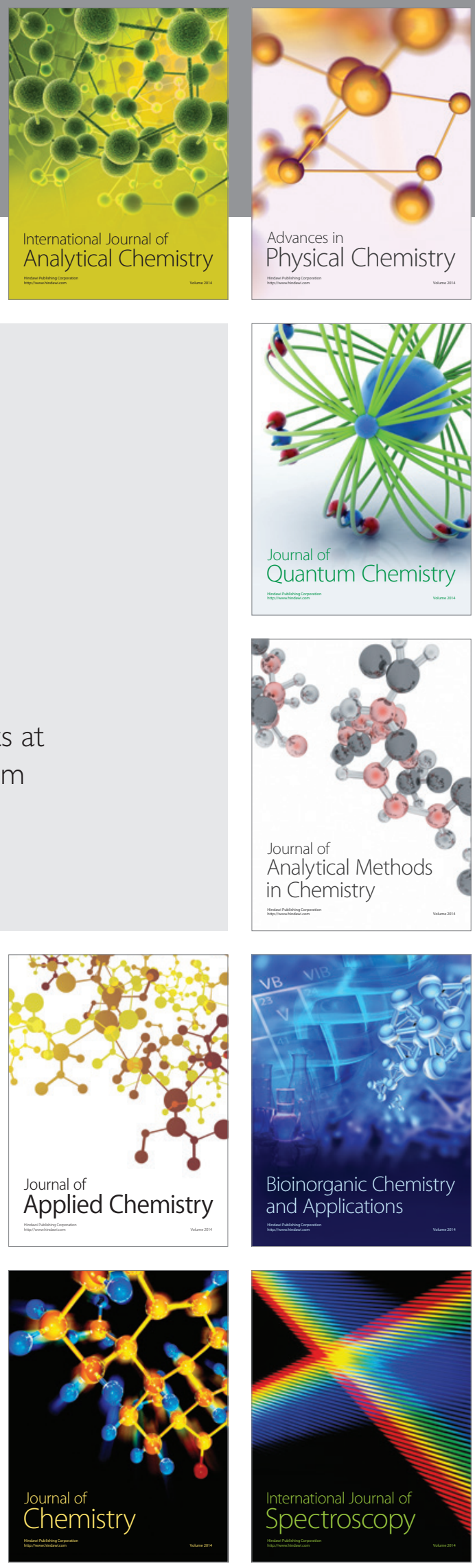